\title{
EFFECT OF THE INHIBITOR OF ANGIOTENSIN I CONVERTING ENZYME ON ENDOCRINE FUNCTION AND RENAL PERFUSION IN HAEMORRHAGIC SHOCK
}

\author{
M. Yamashita, T. OYama, AND T. Kudo ${ }^{\circ}$
}

\begin{abstract}
MANY PHESSOR substances such as catecholamines, vasopressin and angiotensin are liberated during haemorrhagic hypotension, and these substances cause severe vasoconstriction which leads to decrease in tissue perfusion. To alleviate this vasoconstriction and to improve tissue perfusion, phenoxybenzamine ( $\mathrm{POB}$ ), an $\alpha$-adrenergic blocker, has been tried for the treatment of haemorrhagic shock. ${ }^{1}$ However, success in the treatment of shock with POB has been limited. ${ }^{1}$

Recently, Errington and Rocha E. Silva ${ }^{2}$ reported remarkably improved survival rates from haemorrhagic shock in dogs treated with an inhibitor of angiotensin I converting enzyme (SQ20881 - Bradykinin Potentiating Factor, - BPF 9 ) which blocks the conversion of angiotensin I to angiotensin II. Prevention of vasoconstriction induced by angiotensin II may lead to improved tissue perfusion and, ultimately, to a good survival rate. Therefore, we evaluated the effect of inhibition of angiotensin I converting enzyme on renal perfusion and endocrine responses in haemorrhagic shock in dogs.
\end{abstract}

\section{METHOD}

Sixteen mongrel dogs of both sexes weighing 7.0 to $13.0 \mathrm{~kg}$ were used for the experiment. They were anaesthetized by intravenous injection of $30 \mathrm{mg} / \mathrm{kg}$ sodium pentobarbitone. Following tracheal intubation, controlled ventilation was instituted with air using Aika R-40 Ventilator so as to maintain $\mathrm{Pa}_{\mathrm{CO}_{2}} 35$ to $45 \mathrm{~mm} \mathrm{Hg}$. The right femoral artery was cannulated and connected to a transducer (San-ei Type 1236) to measure mean arterial pressure (MAP). The left femoral artery was also cannulated for bleeding and for sampling of blood. A catheter was introduced into the inferior vena cava through the left femoral vein for blood sampling of plasma renin activity (PRA) and for the infusion of fluid. Lactated Ringer's solution $0.1 \mathrm{ml} / \mathrm{kg} / \mathrm{min}$ was infused throughout the procedure.

Following laparotomy, a heated thermocouple probe (San-ei needle type element, type N-56) was inserted into the left renal cortex to measure blood flow according to the method described by Hirasawa. ${ }^{3}$

After the first blood sample was obtained, the dog was shocked by arterial bleeding to lower the MAP to $50 \mathrm{~mm} \mathrm{Hg}$ in 30 minutes. The inhibitor of the angiotensin I converting enzyme SQ208814 (Squibb \& Sons) $1.5 \mathrm{mg} / \mathrm{kg}$ diluted in $5 \mathrm{ml}$ of saline, was administered intravenously to eight dogs (SQ20881-treated group) at the end of haemorrhage, and the same volume of saline was administered to another eight dogs (control group).

'Department of Anaesthesia, Hirosaki University School of Medicine, Hirosaki, Aomori-ken, Japan. 
The animal was observed for 60 minutes following haemorrhage, then $20 \mathrm{ml} / \mathrm{kg}$ of lactated Ringer's solution heated to body temperature was infused in 15 minutes to restore the blood pressure.

Except for the samples for PRA, blood was collected seven times from a cannulated femoral artery with simultaneous replacement of saline. This sampling was done before haemorrhage $\left(S_{1}\right)$, at the end of haemorrhage $\left(S_{2}\right), 15\left(S_{3}\right), 30\left(S_{4}\right)$, and $60\left(\mathrm{~S}_{5}\right)$ minutes after haemorrhage, $15\left(\mathrm{~S}_{6}\right)$ and $45\left(\mathrm{~S}_{7}\right)$ minutes after the completion of infusion. Blood samples for PRA were collected at the same time through the venous catheter. After the last sampling, the dog was sacrificed by administration of magnesium sulfate. Blood flow in renal cortical tissue was expressed as percentage change between pre-haemorrhage (100 per cent) and after death ( 0 per cent).

The determination of plasma vasopressin (VP) concentration was made by the radioimmunoassay method described by Kudo, et al. ${ }^{5}$ The coefficient of variation (c.v.) of this method was 11 per cent. Plasma renin activity (PRA) was determined by radioimmunoassay with a commercially available radioimmunoassay kit (Dainabot RENIN RIAKIT) which was based on the method of Haber, et al. ${ }^{6}$ The c.v. of this method was 7.5 per cent. Plasma aldosterone was measured with a commercially available radioimmunoassay kit (Green-Cross Aldosterone H-3 Kit) which was based on the method of Makenzie and Clements. ${ }^{7}$ The c.v. of this method was 9 per cent.

Mean values have been expressed with the standard error (S.E.) of the mean as the index of dispersion. The student's t-test for paired observations was employed for evaluation of the data. In these results, data indicated to be statistically significant have $p$ values less than 0.05 .

\section{RESUlts}

Mean arterial pressure (MAP) during procedure is depicted in Figure 1. After the haemorrhage, a significant compensatory rise in MAP was observed in the control group. However, in the group treated with SQ20881 this rise was not statistically significant. The difference in MAP between the two groups was significant. Renal cortical tissue blood flow (RBF) of the SQ20881-treated group was significantly lower than that of control group at 30 and 60 minutes after the haemorrhage and 15 minutes after the infusion (Table I).

Haemorrhage produced sharp increase in plasma vasopressin (VP) levels in both groups, but these elevations lasted for only a short period. Significant elevation in plasma renin activity (PRA) was observed following haemorrhage. Plasma aldosterone levels showed 2.4- to 2.5-fold increase following haemorrhage. These elevations lasted until lactated Ringer's solution was infused. However, no significant differences were recognized between the two groups for plasma level of VP or aldosterone, or PRA for each of the sampling times during the experiment (Table II). There were no significant differences between the two groups for $\mathrm{Pa}_{\mathrm{CO}_{2}}, \mathrm{~Pa}_{2}$, plasma concentrations of $\mathrm{Na}^{+}, \mathrm{K}^{+}$, plasma osmolality, arterial $\mathrm{pH}$, urine concentrations of $\mathrm{Na}^{+}, \mathrm{K}^{+}$, or urine osmolality for each of the sampling times. 


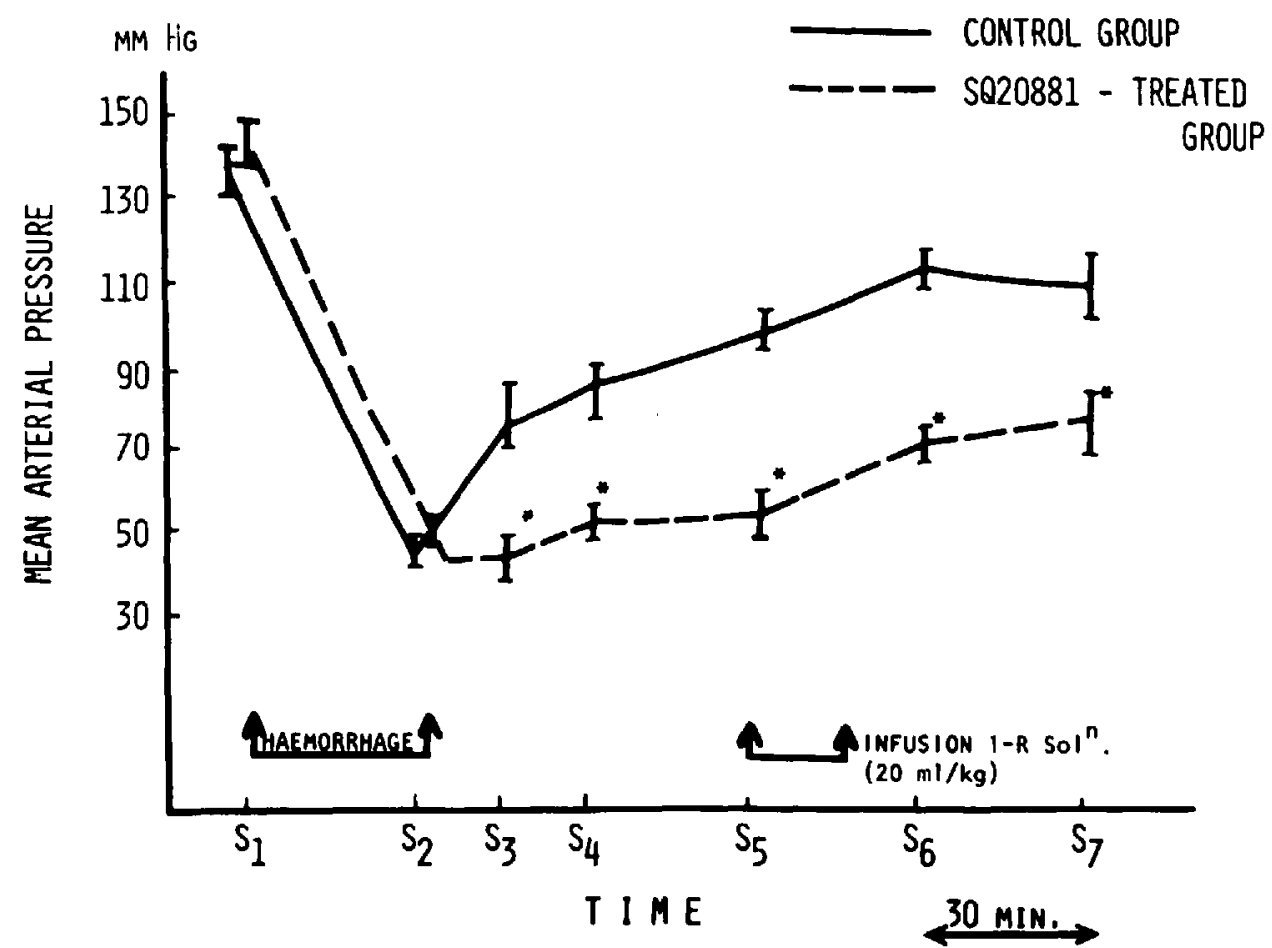

FICURE 1. The effect of inhibition of angiotensin I converting enzyme in haemorrhagic shock in dog as reflected by alternations in mean arterial pressure by treatment with SQ20881.

$S_{\mathrm{l}}$ Pre-haemorrhage (control).

$\mathrm{S}_{2}$ Completion of haemorrhage.

$\mathrm{S}_{3}$ Post-haemorrhage $15 \mathrm{~min}$.

S. Post-haemorrhage $30 \mathrm{~min}$.

$\mathrm{S}_{\text {i }}$ Post-haemorrhage $60 \mathrm{~min}$.

$S_{0}$ Post-infusion $15 \mathrm{~min}$.

$\mathrm{S}_{7}$ Post-infusion $45 \mathrm{~min}$.

※ Statistically significant compared with control.

\section{Discussion}

Administration of an inhibitor of angiotensin I converting enzyme (SQ20881) induced significant delay and decrease in a compensatory rise in blood pressure following haemorrhage as reported by Erdös, et al. ${ }^{8}$ This would indicate that an initial recovery of blood pressure is partly regulated by angiotensin II. Plasma renin activity (PRA) increases in response to various stimuli, such as haemorrhage and surgical stress. ${ }^{9}$ Even pentobarbitone anaesthesia alone was reported to evoke a 5-fold rise of PRA in dogs. ${ }^{10}$ The relatively high PRA values before haemorrhage in our study, compared with those values $(0.8 \mathrm{ng} / \mathrm{ml} / \mathrm{hr})$ in conscious, nonsurgically manipulated dogs reported by Johnson and Malvin, ${ }^{10}$ might be caused by pentobarbitone anaesthesia and surgical stress. Miller, et al. ${ }^{11}$ reported that the administration of inhibitor of angiotensin I converting enzyme increased the levels of renin in blood, probably by eliminating the feed-back inhibition of release of renin by circulating angiotensin II. This negative feed-back mechanism would 


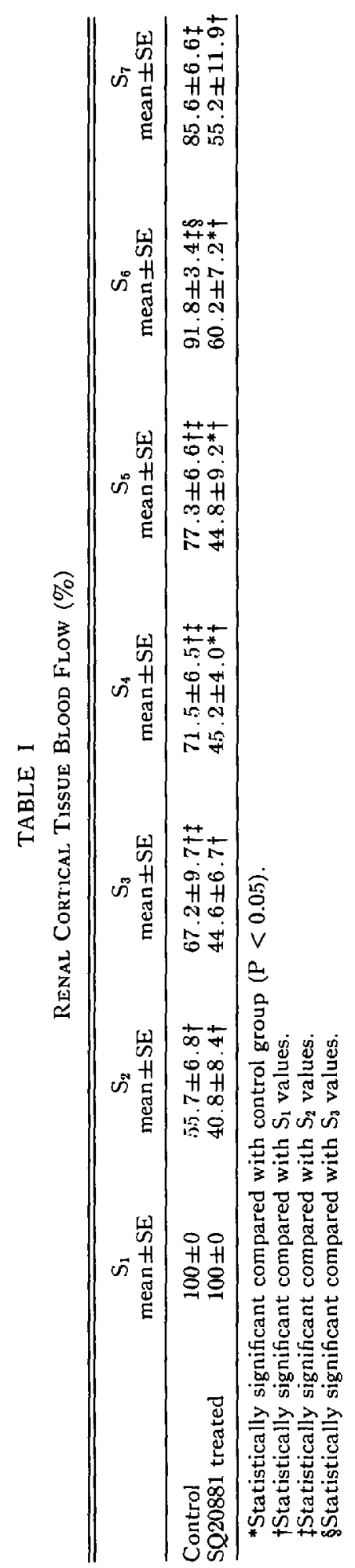




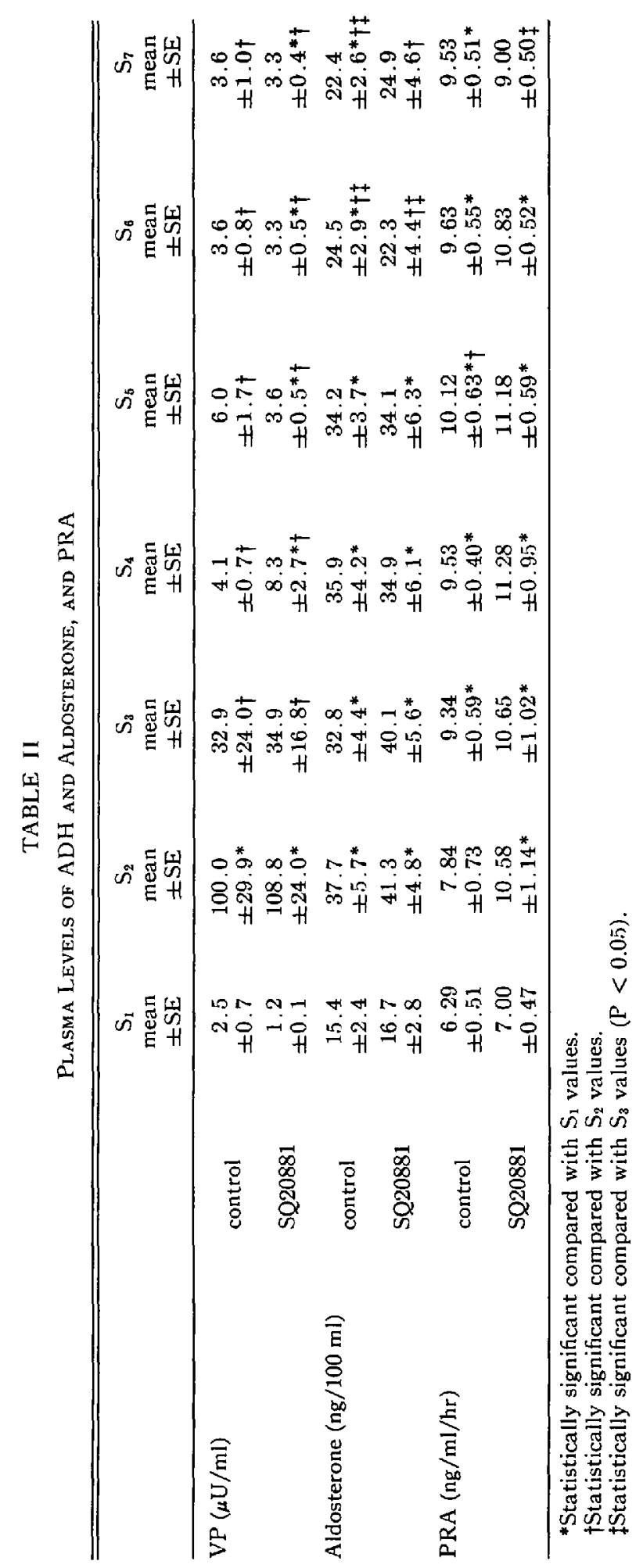


not have been activated during the acute stress of haemorrhage because no significant difference was detected in PRA between the group treated with SQ20881 and the control.

Although it is suggested that the renin-angiotensin system regulates vasopressin (VP) secretion, ${ }^{12,13}$ our data showed no significant differences in plasma vasopressin levels between the SQ20881-treated and the control group. This might imply that angiotensin II plays little role in the regulation of vasopressin secretion during haemorrhage.

Recent evidence suggests that angiotensin II and vasopressin may play a role in irreversible haemorrhagic shock. ${ }^{2,14,15}$ Surprisingly good survival rates in haemorrhagic shock were reported in dogs treated with SQ20881 and in dogs with diabetes insipidus. ${ }^{2}$ The beneficial effect of $\$$ Q20881 was attributed to the prevention of vasoconstriction. Another report speculated a possible involvement of angiotensin II in the cardiac failure observed in haemorrhagic shock. ${ }^{14}$ Infusion of large amounts of angiotensin II has been proved to cause focal necrosis in the cardiac muscles and acute renal failure because of its strong vasoconstrictive property. ${ }^{15}$ Although intestinal vasoconstriction is thought to be responsible for the development of irreversible haemorrhagic shock, phenoxybenzamine (POB) has been proved to be ineffective to release mesenteric vasoconstriction induced by haemorrhage ${ }^{16}$ Circulating angiotensin II and vasopressin were reported to be responsible for the contraction of the intestinal resistance vessel after haemorrhage, ${ }^{16}$ and the intestinal vasoconstriction was shown to be prevented by SQ20881. ${ }^{17}$

We intended to prove a beneficial effect of SQ20881 on renal perfusion, since the kidney is one of the target organs in shock. Noradrenalin-induced cortical vasoconstriction in the kidney was reported to be mediated by activation of both the renin-angiotensin system and $\alpha$-adrenergic receptors. ${ }^{18}$ In contradiction to our expectation that SQ20881 would increase renal blood flow by the prevention of renal vasoconstriction during haemorrhagic hypotension, our data demonstrated a decrease in renal blood flow in the SQ20881-treated group. Bailie and Barbour ${ }^{19}$ observed that the infusion of SQ20881 resulted in a decrease in mean systemic blood pressure, and a significant fall in glomerular filtration rate. Considering their report and our data, inhibition of angiotensin I converting enzyme seems to have no beneficial effect on renal perfusion.

\section{SUMMARY}

The present study was undertaken to investigate the effect of inhibition of angiotensin I converting enzyme on endocrine responses and renal perfusion in haemorrhagic shock. Plasma levels of vasopressin (VP), aldosterone, and plasma renin activity (PRA), and renal cortical tissue blood flow were measured both in control dogs and in those treated with an inhibitor of angiotensin I converting enzyme (SQ20881). The drug was administered with an intention of preventing vasoconstriction induced by angiotensin II and to improve tissue perfusion.

No significant differences were found in plasma levels of vasopressin, aldosterone and plasma renin activity between control and SQ20881-treated groups. Secondary 
elevation of blood pressure following haemorrhage was significantly delayed and reduced by the administration of the inhibitor. Decrease in renal cortical tissue blood flow was observed in the SQ20881-treated group. It is suggested that angiotension II appears to play a role in spontaneous recovery of arterial blood pressure following haemorrhage. Furthermore, angiotensin II does not seem to play an important role in the stimulation of secretion of vasopressin in response to haemorrhage. Our data failed to demonstrate any favourable effects of inhibition of angiotension I converting enzyme on renal perfusion during haemorrhagic shock in dogs.

\section{REFERENCES}

1. Chien, S. Role of the sympathetic nervous system in hemorrhage. Physiol. Rev. 47: 214 (1967).

2. Errington, M.L. \& Rocha E. Silva, M. Jr. On the role of vasopressin and angiotensin in the development of irreversible haemorrhagic shock. J. Physiol. 242: 119 (1974).

3. Hirasawa, $H$. Effects of anesthetics on blood flow of the renal cortex and medulla. Jap. J. Anesth. 20: 539 (1971).

4. Erdös, E.G. Conversion of angiotensin I to angiotensin II. Am. J. Med, 60: 749 (1976).

5. Kudo, T., Kudo, M., \& Oyama, T. Radioimmunoassay for vasopressin in blood. Clin. Endocr. (Tokyo) 24: 1311 (1976).

6. Haber, E., Koerner, T., Page, L.B., Kliman, B., \& Punnode, A. Application of radioimmunoassay for angiotensin I to the physiologic measurements of plasma renin activity in normal human subjects. J. Clin. Endocrinol. Metab. 29: 1349 (1969).

7. Makenzie, J.K. \& Clements, J.A. Simplified radioimmunoassay for serum aldosterone utilizing increased antibody specificity. J. Clin. Endocrinol. Metab. 38: 622 (1974).

8. Endös, E.G., Massion, W.H., Downs, D.R., \& Gecse, A. Effect of the inhibition of angiotensin I converting enzyme in endotoxin and hemorrhagic shock. Proc. Soc. Exp. Biol. Med. 145: 948 (1974).

9. Davis, J.O. \& Freeman, R.H. Mechanisms regulating renin release. Physiol. Rev. 51: 1 (1976).

10. Johnson, M.D. \& MaLvin, R.L. Plasma renin activity during pentobarbital anesthesia and graded hemorrhage in dogs. Am. J. Physiol. 229: 1098 (1975).

11. Miller, E.D. Jr., Samuels, A.I., Haber, E., \& Barger, A.C. Inhibition of angiotensin conversion and prevention of renal hypertension. Am. J. Physiol. 228: 448 (1975).

12. Bonjour, J.P. \& Malvin, R.L. Stimulation of ADH release by the renin-angiotensin system. Am. J. Physiol, 218: 1555 (1970).

13. Mouw, D., Bonjour, J.P., Malvin, R.L., \& Vander, A.J. Central action of angiotensin in stimulating ADH release. Am. J. Physiol. 220: 239 (1971).

14. Monton, J.J., Lever, A.F., Ledingham, I.McA, Tehrani, M.A., Stuart, B., Reyes, A., \& MCGarrity, C. Angiotensin I, Angiotensin II and arginine vasopressin in experimental hemorrhagic shock. Acta. Endocr. 80 (Supple. 199): 404 (1975).

15. Gavras, H., Khemer, D., Bhown, J.J., Gray, B., Lever, A.F., MacAdam, R.F., Medina, A., Monton, J.J., \& Robertson, J.I.S. Angiotensin- and norepinephrine-induced myocardial lesions: experimental and clinical studies in rabbits and man. Am. Heart J. 89: 321 (1975).

16. MCNell, J.R., StartK, R.D., \& Greenway, C.V. Intestinal vasoconstriction after hemorrhage: role of vasopressin and angiotensin. Am. J. Physiol. 219: 1342 (1970).

17. MCNeIL, J.R. Intestinal vasoconstriction following diuretic induced volume depletion. Role of angiotensin and vasopressin. Can. J. Physiol. Pharmacol. 52: 829 (1974).

18. Bomzon, L. \& Rosendorf, C. Renovascular resistance and noradrenaline. Am. J. Physiol. 229: 1649 (1975).

19. BaIlie, M.D. \& Barbour, J.A. Effect of inhibition of peptidase activity on distribution of intrarenal blood flow. Am. J. Physiol. 228: 850 ( 1975). 